\title{
Algumas reflexões Sobre relacionamentos AFETIVOS E RELAÇÕES SEXUAIS NA ADOLESCÊNCIA
}

\author{
Elaine Italiano Vidal ${ }^{\star}$ \\ Paulo Rennes Marçal Ribeiro ${ }^{\star \star}$
}

\begin{abstract}
Resumo
Sexo e sexualidade são temas bastante abordados pela sociedade e suas instituições, desde a mídia até a universidade. Também a escola de ensino fundamental e médio vem sendo apontada como espaço propicio para se trabalhar com orientação sexual, considerando inclusive as questões em voga como a gravidez não planejada na adolescência, as relações de gênero, o combate à homofobia e as doenças sexualmente transmissiveis, particularmente a AIDS. O presente trabalho é resultado de uma pesquisa realizada com adolescentes de 14 a 19 anos, estudantes de uma escola pública de ensino médio, tendo como objetivos verificar como pensam e se comportam os jovens frente a questões e atitudes que envolvem sexo e sexualidade. A técnica de coleta de dados foi a redação, em que os sujeitos escreveram sobre idéias, práticas e comportamentos sexuais, sendo que no recorte feito para a apresentação deste artigo, nos prendemos aos relacionamentos afetivos e relações sexuais.
\end{abstract}

Palavras-chave: adolescência; sexualidade; sexo; comportamento sexual; escola pública.

\section{SOME CONSIDERATIONS ABOUT RELATIONSHIPS AND SEXUAL INTERCOURSES IN ADOLESCENCE}

\begin{abstract}
Sex and sexuality are subjects that have been discussed at great length by society and its institutions, media and university in several ways. The school is requested to deal with this important subject, given the aggravation of some questions involving sex, for example teenage pregnancy, diseases transmitted by sex (mainly AIDS) and questions about gender and homosexuality. The target of this article is the adolescent, who is in bio-psychic-social changes and,

^ Pedagoga. Mestre em Educação Escolar e integrante do Núcleo de Estudos da Sexualidade na Faculdade de Ciências e Letras da Universidade Estadual Paulista - UNESP.

E-mail: elaineitaliano@gmail.com

$\star \star$ Psicólogo. Doutor em Saúde Mental e Livre-Docente em Sexologia e Educação Sexual. Professor-Adjunto e Coordenador do Núcleo de Estudos da Sexualidade na Faculdade de Ciências e Letras da Universidade Estadual Paulista - UNESP.

E-mail: paulorennes@pq.cnpq.br
\end{abstract}


sometimes, in emotionally, social and physically disturbed situation. This work is a result of a research carried out with teenager students in the $14-19$ age range, from a public high school. The general aims of the work were to verify how the students think and behave in situations concerning sex and sexuality. The methodology used was analysis of redactions written by the students where they described their sexual ideas and behaviors, evidencing values, taboos, myths, prejudgments and difficulties.

Keywords: adolescence; sexuality; sex; sexual behavior; public school.

\section{INTRODUÇÃO}

Este trabalho é resultado de uma pesquisa realizada com adolescentes estudantes do ensino médio de uma escola pública estadual de um município localizado no interior do estado de São Paulo, que teve como objetivos gerais verificar como pensam e como se comportam os jovens atualmente no que diz respeito a sexo e sexualidade, e discutir à luz de referenciais teóricos sobre as concepções que possuem, adquiridas ao longo de suas vidas por meio da educação sexual. Foi possível então, evidenciar valores morais, tabus e preconceitos que permeiam estas concepções, além de uma contraditoriedade entre o falar e o agir, entre o proclamado e o desejado, contida nas idéias e nas práticas sexuais.

A pesquisa foi realizada de maneira a conciliar aspectos característicos da abordagem quantitativa e da abordagem qualitativa, pois:

[...] a relação desejada entre o quantitativo com o qualitativo pode ser considerada complementar. Ou seja, enquanto o quantitativo ocupa-se de ordens de grandezas e de suas relações, o qualitativo é um quadro de interpretações para medidas ou a compreensão para o não quantificável. (SILVA, 1998, p.171).

O instrumento para a coleta dos dados foi a redação. Os sujeitos desenvolveram cada um uma redação sobre o assunto sexo e sexualidade. A escolha pela redação deu-se por diversos motivos. Primeiramente pelo fato do assunto ser diretamente relacionado à individualidade do sujeito, a diferentes modos de pensar e agir, e de ser carregado de regras de comportamento e valores morais e sociais, e então ao escrever sem ser identificado, o aluno poderia sentir maior liberdade sem ter a preocupação de ser alvo de julgamentos. E a intenção era de que o aluno pudesse escrever sobre o que quisesse, sem muita interferência ou sugestões que, por exemplo, um questionário ou entrevista poderia proporcionar. Outro fator responsável pela escolha da redação é que se pretendeu atingir um maior número de alunos na escola, o que seria inviável por meio de entrevistas.

A redação adequou-se ao que Bogdan e Biklen (1999, p. 176) colocam sobre os Documentos Pessoais: "o material escrito pelos próprios sujeitos da pesquisa é chamado de Documentos Pessoais e embora seja de costume utilizá- 
lo como dados que representam parte do estudo, pode também ser utilizado em exclusivo". Estes documentos referem-se a "qualquer narrativa feita na primeira pessoa que descreva as ações, experiências e crenças do indivíduo, sendo autorevelador da visão que a pessoa possui” (BOGDAN; BIKLEN, 1999, p. 177).

O número de sujeitos foi estabelecido pelo método de Krejcie e Morgan (1970) a partir do total de 740 alunos da escola, que apontam, por meio de uma tabela, os números de amostras correspondentes ao tamanho da população pretendida. Os autores afirmam que esta tabela foi elaborada por meio de uma fórmula estatística desenvolvida pela National Education Association. No caso da população aqui em questão, o número de alunos necessário para a amostra era de aproximadamente 254. Foram coletadas 255 redações.

Os sujeitos desta pesquisa foram alunos e alunas do ensino médio, período diurno, de uma escola pública estadual localizada em um município do interior do estado de São Paulo. Estes alunos e alunas encontravam-se em idade entre 14 e 19 anos e o critério para esta escolha foi justamente o fato de que nesta faixa etária o jovem está no ápice das transformações bio-psico-sociais e em fase de formação de conceitos que o acompanharão modificando-se ou não em sua vida sexual, social e política. Nos quadros e tabelas os sujeitos são identificados pela letra $\mathrm{M}$ - quando do sexo masculino ou $\mathrm{F}$ - quando do sexo feminino, seguida por um número que corresponde à quantidade de sujeitos.

A parte quantitativa abarcou o que os sujeitos escreveram e a respectiva tabulação de dados, cálculos de porcentagem e elaboração de tabelas e gráficos, a partir da análise qualitativa do que escreveram.

A interpretação qualitativa foi feita tendo como norte e embasamento teórico os pressupostos de Bardin (1977, p. 42) por meio da análise de conteúdo:

[...] um conjunto de técnicas de análise das comunicações, visando obter, por procedimentos, sistemáticos e objetivos de descrição do conteúdo das mensagens, indicadores (quantitativos ou não) que permitam a inferência de conhecimentos relativos às condições de produção/recepção (variáveis inferidas) destas mensagens.

Para este procedimento seguimos as seguintes etapas: 1- a descrição, podendo-se obter por ela a caracterização geral dos documentos (as redações), o que corresponde àqueles procedimentos acima mencionados. 2- a inferência, que é a principal intenção da análise de conteúdo, se dá por meio de deduções lógicas de conhecimentos sobre o emissor da mensagem ou sobre seu meio, e resulta em saberes de natureza psicológica, sociológica, histórica, econômica. 3- a interpretação, a terceira e última etapa, que é a significação atribuída ao conteúdo.

A pesquisa qualitativa permite captar a realidade e o discurso próprio do sujeito, como afirmam Bogdan e Biklen (1999). Extrema importância é dada à maneira como as pessoas dão sentido às suas vidas, e apreender as diferentes perspectivas adequadamente torna-se crucial. O objetivo do pesquisador qualita- 
tivo em educação deve ser o de perceber aquilo que os sujeitos experimentam, o modo como interpretam suas experiências e o modo como eles próprios estruturam o mundo social em que vivem.

A união das abordagens quantitativa e qualitativa nesta pesquisa possibilitou que os dados obtidos fossem suficientes e satisfatórios para que se pudesse obter uma análise de resultados fidedigna e, "grosso modo", generalizável.

\section{RELACIONAMENTOS E RELAÇÕES SEXUAIS}

Este tema reúne as redações que tiveram colocações dos (as) alunos (as) sobre como o sexo está sendo feito, ou encarado pelos jovens de maneira geral e como deve ou deveria ser feito. Então eles falam sobre relações sexuais e relacionamentos que envolvem ou não o ato sexual. Dessa forma, mostram como eles mesmos encaram estes relacionamentos e não somente como "os jovens" de hoje encaram.

Figura. 1. Relacionamentos e relações sexuais: ocorrência do tema no universo pesquisado

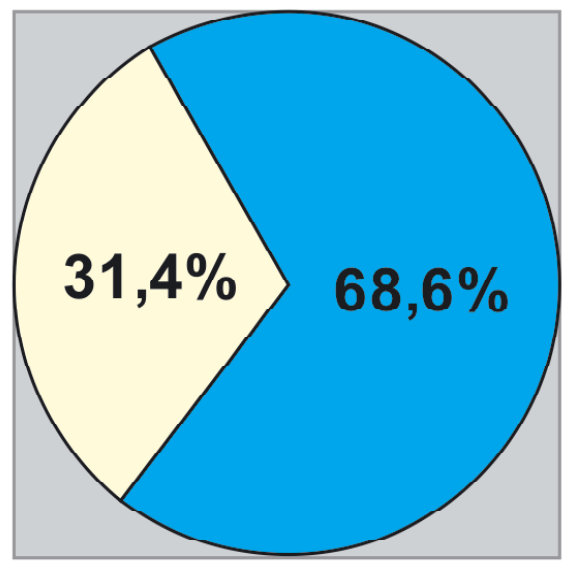

Relacionamentos e relações sexuais

$\square$ Redações que não abordaram o tema

Tabela 1. Relacionamentos e relações sexuais: ocorrência do tema no universo pesquisado.

\begin{tabular}{|l|c|c|c|}
\hline & Fem & Mas & Total \\
\hline $\mathrm{N}^{0}$ Total de Redações & $\mathbf{1 4 3}$ & $\mathbf{1 1 2}$ & $\mathbf{2 5 5}$ \\
\hline $\mathrm{N}^{0}$ Redações que abordaram o tema & $\mathbf{1 0 0}$ & $\mathbf{7 5}$ & $\mathbf{1 7 5}$ \\
\hline Percentual das redações que abordaramo tema & $\mathbf{6 9 , 9}$ & $\mathbf{6 7 , 0}$ & $\mathbf{6 8 , 6}$ \\
\hline
\end{tabular}

Este tema foi bastante abordado pelos alunos e alunas, como mostra a figura 1. A figura 2 aponta que se comparando os dois sexos, a diferença entre eles é mínima: 
Algumas reflexões sobre relacionamentos afetivos e relações sexuais na adolescência

Figura 2. Relacionamentos e relações sexuais: ocorrência do tema por sexo.

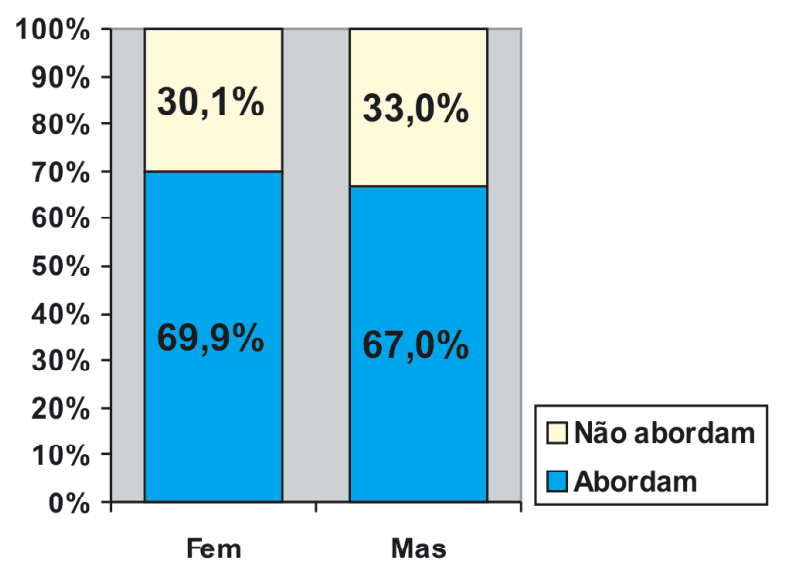

Ao observar a tabela 2, ficará mais claro sobre o que exatamente os alunos e alunas falam para estarem consideradas neste tema.

Tabela 2. O que os alunos e alunas escreveram sobre Relacionamentos e relações sexuais`

\begin{tabular}{|c|c|c|c|c|c|c|}
\hline \multirow{3}{*}{$\begin{array}{l}\text { Categoria Sexo por amor } \\
\text { Sub-Categorias: }\end{array}$} & \multirow{2}{*}{\multicolumn{2}{|c|}{$\begin{array}{c}\text { Fem } \\
\mathrm{N}-100\end{array}$}} & \multirow{2}{*}{\multicolumn{2}{|c|}{$\begin{array}{c}\text { Mas } \\
N-75\end{array}$}} & \multirow{2}{*}{\multicolumn{2}{|c|}{$\begin{array}{c}\text { Totais } \\
\mathrm{N}-175\end{array}$}} \\
\hline & & & & & & \\
\hline & $\mathbf{N}^{0}$ & $\%$ & $\mathbf{N}^{0}$ & 0 & $\mathbf{N}^{0}$ & $\%$ \\
\hline $\begin{array}{l}\text { 1- Jovens transam com "qualquer um", só pelo } \\
\text { prazer, sem amor, sem compromisso, só por } \\
\text { divcrsáo. }\end{array}$ & 45 & 45,0 & 17 & 22,7 & 62 & 35,4 \\
\hline $\begin{array}{l}\text { 7- Sexo hoje é normal, lilxerado, comum, fácil, } \\
\text { simples para os jovens. }\end{array}$ & 36 & 36,0 & 19 & 25,3 & 55 & 31,4 \\
\hline $\begin{array}{l}\text { 3- Sexo deve ser feito na hora certa, com a pessoa } \\
\text { ccrta (com amor) c considcram a prevenção. (scxo } \\
\text { seguro com amor) }\end{array}$ & 30 & 30,0 & 14 & 18,7 & 44 & 25,1 \\
\hline $\begin{array}{l}\text { 4- Jovens pensam muito em sexo, ou só pensam em } \\
\text { sexo. }\end{array}$ & 16 & 16,0 & 15 & 20,0 & 31 & 17,7 \\
\hline $\begin{array}{l}\text { 5- Sexo deve ser feito com amor, com a pessoa certa } \\
\text { (não consideram prevenção). }\end{array}$ & 13 & 13,0 & 11 & 14,7 & 24 & 13,7 \\
\hline 6- Sohre $n$ sexn no "ficar" & 8 & 8,0 & 2 & 2,7 & 10 & 5,7 \\
\hline $\begin{array}{l}\text { 7- Sexo nào é tudo na vida, näo é essencial num } \\
\text { rclacionamcnto. }\end{array}$ & 7 & 7,0 & 3 & 4,0 & 10 & 5,7 \\
\hline $\begin{array}{l}\text { 8- Sexo deve ser feito somente com compromisso } \\
\text { entre os dois (namorando). }\end{array}$ & 5 & 5,0 & 2 & 2,7 & 7 & 4,0 \\
\hline 9- Sexo possui um papel import ante: a reprodução & 1 & 1,0 & 3 & 4,0 & 4 & 2,3 \\
\hline \multicolumn{7}{|l|}{ Categoria Sexo por prazer } \\
\hline Sub-Categorias: & $\mathbf{N}^{0}$ & $\%$ & $\mathbf{N}^{0}$ & $\%$ & $\mathbf{N}^{0}$ & $\%$ \\
\hline 10- Dizem que sexo é bom, gostoso, essencial & 14 & 14,0 & 22 & 29,3 & 36 & 20,6 \\
\hline $\begin{array}{l}\text { 11- Scxo pode scr teito com ou scm amor. (São os } \\
\text { que dizem que pode ser feito só por prazer) }\end{array}$ & 1 & 1,0 & 4 & 5,3 & 5 & 2,9 \\
\hline
\end{tabular}

*Muitas vezes as redações são consideradas em mais de uma categoria, portanto não há como apresentar uma somatória dos totais das categorias. 


\section{SEXo POR AMOR}

A subcategoria 1 é a mais numerosa, com 62 alunos (as), ou equivalente a $35,4 \%$ do total de alunos (as) que abordam este tema, e considera as redações nas quais os mesmos dizem que os "jovens transam com qualquer um, só pelo prazer". O contexto destas redações mostra que estes alunos e alunas estão criticando este comportamento nos jovens, isto é, eles estão falando isto de maneira a deixar claro na redação que não concordam com este comportamento (os que não criticam não foram considerados nesta subcategoria e sim na subcategoria 11, na qual estão os que dizem que o sexo pode ser feito só por prazer). Vale ressaltar que mais alunas que alunos estão criticando isto nos jovens: $45 \%$ contra $22,7 \%$.

Nas subcategorias 3, 5, e 8 estão os alunos que, além desta crítica, indicam em quais circunstâncias o sexo deve ser feito, além de outros alunos que não criticam, mas que somente indicam estas condições. Então, juntando-se as subcategorias 1, 3, 5 e 8, desconsiderando as redações repetidas, temos uma grande quantidade de alunos e alunas que, de uma forma ou de outra, mostram-se com opiniões contrárias ao sexo só pelo prazer, indicando que ele deva ser feito somente quando houver amor.

Além destas, outras subcategorias também revelam críticas ao sexo pelo prazer e são defensoras, mesmo que não declaradamente do "sexo por amor", sendo contempladas a seguir.

Também se nota que as redações de meninas são mais freqüentes neste aspecto. E muitas vezes são preconceituosas, refletindo e reproduzindo idéias machistas que inferiorizam a si mesmas. Exemplo a seguir de garota que escreve criticando as meninas que transam para poder contar às amigas, coisa que os meninos costumam fazer, com a autorização da sociedade:

[...] acho errado que muitas adolescentes transam com qualquer garoto achando que é legal, e também para poder contar para as amigas no dia seguinte, garotas desse tipo tem todos os garotos a seus pés e pensa que nunca vão ficar sozinhas, pois acham que os garotos as amam e morrem por elas. Mas esses meninos só ficam atrás delas porque sabem que vão conseguir com elas o que querem, mas quando eles quiserem uma namorada, não será ela a escolhida, afinal de contas nenhum menino vai querer aquela garota que já passou na mão de todos, pelo contrário, ele vai querer uma que seja legal e certa, talvez não que seja virgem, mas que tenha um certo mistério e não que todos usem e abusem (sic) (F8).

Na subcategoria 1, alguns alunos que criticam o sexo pelo prazer o fazem associando-o a conseqüências como gravidez, doenças, como se o sexo por amor estivesse por si só imune a isto.

[...] é preciso de um companheiro que você ame e que também seja amada é assim que penso, pois tem muitas garotas de 
minha idade que fazem por um simples prazer e já estão com filhos nos braços e eu não quero isto pra mim, mas não que esteja julgando as outras de uma maneira vulgar, mas que se você quer fazer faça com responsabilidade e com a certeza que você quer e não por fazer (sic) (F55).

Esta aluna associa o sexo pelo prazer à gravidez, quando diz "fazem por um simples prazer e já estão com filhos nos braços", porém parece saber que a falta de prevenção é que pode resultar nisto, ao referir-se também na redação à necessidade de se ter "responsabilidade" e a sexo com "alta proteção". Esta dualidade pode indicar uma ambivalência de valores em relação a esta questão do sexo pelo prazer. O jovem não sabe se apóia ou não o sexo pelo prazer com proteção, ou se encara isto como "imoral" e assim somente o sexo por amor é o que seria correto.

Outros alunos também fazem esta relação entre o sexo pelo prazer e gravidez e DSTs:

Na verdade o jovem de hoje não tem muita preocupação com as coisas e nem se 'prendem' as pessoas, o que eu acho uma pena; porque é por isso que muito jovem hoje tem Dsts, engravidam cedo. Ninguém se preocupa com nada (sic) (F11).

Há os que criticam o fato dos jovens transarem com qualquer um, apontando que o problema é a falta de prevenção:

Os jovens de hoje só pensam em sair, ir para as baladas, encontrar um (a) parceiro (a) para passarem a noite juntos, para transarem, e o pior, a maioria não usam camisinha, aí a tal da gravidez, que quando não vinda na hora certa só traz preocupações, e também as doenças sexualmente transmissíveis. (sic) (F70).

Na subcategoria 6, Sobre o sexo no "ficar", os alunos $(2,7 \%)$ e alunas $(8 \%)$ dizem que o sexo quando ocorre neste tipo de relacionamento não é legal. Exemplo:

A adolescência é a fase mais confusa e contraditória de um jovem e é nesse período que começam os beijos, abraços, namoros etc., mas atualmente a moda é "ficar". O que antes significava apenas beijinhos, hoje pode ser sinônimo de problemas, pois muitas vezes nesse "ficar" acabam acontecendo o sexo apenas por simples prazer e interesse. $\mathrm{O}$ famoso sexo sem compromisso. Em certos casos não ocorre nenhum tipo de prevenção e é aí que surgem as complicações (sic) (F76). 
De qualquer forma, ao fazerem a crítica aos jovens de maneira geral, estes alunos mostram que acham que o pré-requisito para se ter relacionamentos sexuais seria a escolha do parceiro sexual, de modo que haja reciprocamente o que eles chamam de "amor".

[...] sexo simplesmente por prazer não vale a pena e é algo muito idiota, feio e pobre (sic) (M86).

[...] muitos adolescentes encaram isso (o sexo) como uma forma de curtir a vida e na maioria das vezes nem se importam se vão ou não continuar o resto da vida, ou pelo menos boa parte dela com a pessoa para a qual se entregou, se importam apenas em saber o primeiro nome dela (sic) (F89).

Na subcategoria 3, Sexo deve ser feito na hora certa, com a pessoa certa (com amor) e consideram a prevenção, temos as condições ideais para se ter relações sexuais e elas estão relacionadas a: estar preparado (a) física e psicologicamente, estar com a pessoa que ama e que seja recíproco, e estar prevenido. Também nesta subcategoria mais meninas que meninos indicam isto: $30 \%$ contra $18,7 \%$.

[...] sexo é feito com carinho e amor, e não com brutalidade. Sexo na adolescência tem que ser feito pensado. $1^{\circ} \mathrm{O}$ casal de adolescentes tem que saber se é isso o que eles querem. $2^{\circ}$ Tem que saber se a parceira está segura do que vai fazer. $3^{\circ}$ Tem que usar camisinha (sic) (M63).

A subcategoria 5, Sexo deve ser feito com amor, com a pessoa certa (não consideram prevenção), contém as redações que falam somente do sexo por amor, sem considerar a prevenção.

Sexo é a forma mais bonita de demonstrar o amor que existe entre um casal [...] o sexo só é bom quando é feito com amor e não por obrigação e nem por dinheiro porque nada compra um momento como este (sic) (M81).

Há também as redações que enfatizam a necessidade do compromisso, isto é, ser necessário ter um compromisso, um namoro, com o parceiro para poder ter relações sexuais (subcategoria 8). Nas outras subcategorias que falam do sexo por amor, não aparece o compromisso, portanto, entendo que, para estes alunos, sentir amor pelo parceiro (a) e ser correspondido já é suficiente para se concretizar o ato sexual.

As redações que dizem que sexo não é tudo na vida, não é essencial num relacionamento, também cultuam o amor (subcategoria 7):

[...] eu acho que o sexo na vida de uma pessoa ou mesmo em uma relação não é essencial nem muito menos necessário, tem pessoas que dizem que precisam do sexo ou que o namorado exige manter relações, acho que não é assim [...] (sic) (F87). 
O sexo não é tudo de bom na vida dos jovens, mas sim o amor, mas não quer dizer que não pode fazer sexo, mas tem que ser quando se sentir seguro (sic) (M16).

Jovens pensam muito em sexo, ou só pensam em sexo: aqui também aparece a maneira pejorativa de falar, na subcategoria 4. As redações nesta consideradas dizem que hoje em dia os jovens pensam muito em sexo ou só pensam em sexo. Algumas destas deixam evidente a desaprovação, outras acham isso normal, natural da idade, e até inevitável. Algumas exceções de redações que não falam pejorativamente, por exemplo:

Os jovens só pensam em sexo porque estão mais maduros, mais desenvolvidos e também porque as meninas dão muita bola... eu também penso mas não toda hora (sic) (M19).

O tom de crítica é o que predomina nas redações, isto é, falam como se pensar muito em sexo fosse ruim, prejudicial, pois acaba trazendo problemas, assim como o sexo pelo prazer.

Uma aluna falando de uma amiga: "Só pensa em transar com o namorado, é muito largada" (sic) (F52).

E outra aluna: “[...] o sexo virou um vício [...]" (sic) (F130).

Têm-se na subcategoria 2 consideradas as redações as quais os alunos e alunas disseram, de uma maneira ou de outra, que hoje em dia o sexo é normal na vida dos jovens, ou que há mais facilidades em praticá-lo, ou que é mais liberado que antigamente. Percebe-se, em algumas redações, que há um lamento em relação a isto. Em outras redações não chega a ser um lamento, mas uma ressalva em relação ao fato de que o sexo é encarado como normal, porém sem cuidados, sem preocupações com as conseqüências. Algumas se mostram incoerentes dizendo que "é normal" e depois se contradizendo afirmando "não é normal", ou vice-versa. Isto aparece em duas redações do sexo feminino, como se pode ver:

[...] normal, normal mesmo não é, mas se você estiver preparado não deve haver preconceito nenhum, pois é a coisa mais normal do mundo. Sexo é tudo de bom! (sic) (F29).

No meu caso como já tenho relações com meu namorado de quase 2 anos é normal a sexualidade [...] não façam da sexualidade uma coisa normal, é normal mas na hora certa e com a pessoa certa (sic) (F140).

O que se verifica com esta subcategoria é que os jovens que escreveram estas redações consideram que o sexo é algo normal, porém segundo algumas condições.

$\mathrm{Na}$ minha opinião, o sexo é uma coisa normal, contanto que as pessoas se conheçam e saibam os riscos que correm podendo assim se prevenir contra as DSTs e também a gravidez (sic) (F8). 
Há também tons de lamento: “[...] infelizmente hoje em dia, o sexo já ficou comum na vida dos jovens" (sic) (F4).

E há os que se mostram com opiniões positivas:

Hoje em dia eu acho que a sexualidade é uma coisa normal porque a maioria dos pais conversão com seus filhos sobre o assunto. [...] Eu acho que isso é uma coisa normal e que ninguém tem que se intrometer na vida sexual de ninguém a vida é de cada um, e cada um faz da sua vida o que quer (sic) (M53).

O sexo como sendo considerado essencialmente para reprodução aparece em poucas redações, mas ainda aparece (subcategoria 9, 1\% de meninas contra $4 \%$ de meninos). E vê-se claramente nestas a influência da religiosidade. Esta visão do sexo somente para reprodução tem raízes religiosas, de onde também se originaram tabus como o da virgindade.

O sexo tem um papel muito importante nas nossas vidas que é a reprodução. Mas transformaram-no em uma 'coisa', para algumas pessoas você é um objeto sexual que depois não serve mais (sic) (F75).

\section{SEXO POR PRAZER}

Somente duas categorias podem ser consideradas nesta perspectiva: 10Dizem que sexo é bom, gostoso, essencial e 11-Sexo pode ser feito com ou sem amor: aqui estão as redações que dizem que o sexo pode ser feito só pelo prazer, independentemente de haver amor ou compromisso entre os parceiros.

O percentual das redações da subcategoria 11 é bem pequeno (2,9\%). Somente uma aluna e 4 alunos falam disto, no total de 5 alunos.

O sexo pode ser ou não feito com amor, o importante é sempre o respeito pelo parceiro e os cuidados contra doenças (sic) (F81).

Já na subcategoria 10 há um pouco mais de alunos falando do sexo como sendo fonte de prazer. Estes não salientam amor, e sim o prazer que o sexo proporciona. Então, 14 redações do sexo feminino e 22 do sexo masculino dizem que sexo é bom, gostoso, essencial. Destas, 9 alunas e 8 alunos falam que o sexo é bom, porém com prevenção ou "cuidados". Depoimentos a respeito:

A vida envolve várias coisas, mas ela sem o sexo fica sem graça não fica colorido já pensou a vida sem o sexo não multiplicaria as pessoas e os animais, isso envolve tudo. Até a gente fica um tempo sem sexo a gente não fica bem total, não fica completo, fica vazio sem nexo pra minha pessoa $o$ sexo é uma coisa muito importante [...] (sic) (M80). 
O sexo é bom porque deixa você mais calmo e mais disponível (sic) (M104).

Enfim, o sexo pelo prazer, sem relacionamento amoroso é pouco aceito entre estes jovens. Pelo menos, é o que mostram aqui. Parece haver uma dificuldade em dissociar o sexo do amor, principalmente pelas meninas, isto talvez porque foram educadas sexualmente neste sentido. Então, aos meninos é facultado o poder de transar só pelo prazer e com quantas quiserem e, às meninas é facultado o poder de transar só se houver o "amor". Também o "amor" pode ser a justificativa da qual as meninas se apropriaram para não serem julgadas pela sociedade como "fáceis" quando transarem, pois se for "por amor" o ato sexual é mais bem aceito para elas. Ao mesmo tempo em que isto pode ser configurado como um artifício de defesa ou proteção das meninas, pode-se entender que seja a sujeição das mesmas a este sistema preconceituoso e estereotipado no qual a mulher deve ser contida sexualmente, ao contrário do homem.

Bourdieu (1999) por meio de estudo etnográfico referente à sociedade cabila, enfoca a dimensão simbólica da dominação masculina demonstrando que esta está alicerçada no nosso inconsciente de tal maneira que não é percebida e, portanto, é reproduzida por meio de práticas e estratégias que determinam a construção social dos corpos sendo então incorporada.

$\mathrm{O}$ autor coloca que as práticas e as representações dos sexos masculino e feminino não são simétricas e no que diz respeito ao ato sexual, pelos homens este é concebido:

[...] como uma forma de dominação, de apropriação, de "posse" [e as mulheres são] socialmente preparadas para viver a sexualidade como uma experiência íntima e fortemente carregada de afetividade, que não inclui necessariamente a penetração, mas que pode incluir um amplo leque de atividades (falar, tocar, acariciar, abraçar etc.) (BOURDIEU, 1999, p. 30).

Assim, a relação sexual para Bourdieu:

[...] está construída através do princípio de divisão fundamental entre o masculino, ativo, e o feminino, passivo, e porque este princípio cria, organiza, expressa e dirige o desejo - o desejo masculino como desejo de posse, como dominação erotizada, e o desejo feminino como desejo da dominação masculina, como subordinação erotizada, ou mesmo, em última instância, como reconhecimento erotizado da dominação. (BOURDIEU, 1999, p. 31).

A relação sexual se mostra então como uma relação social de dominação masculina e dessa forma o "amor" pode contribuir a perpetuar esta relação. Pois a mulher é educada para amar e o homem para prioritariamente provar a sua virilidade, mesmo que também ame. 
Tendo isto, e pensando no fato de que as redações das meninas priorizam o amor como fator fundamental para o ato sexual se realizar, procedo à indagação que Bourdieu (1999, p. 129) faz sobre o amor e a dominação:

Seria o amor uma exceção, a única, mas de primeira grandeza, à lei da dominação masculina, uma suspensão da violência simbólica, ou a forma suprema, porque a mais sutil e a mais invisível, desta violência?

Vejo que o amor nesta perspectiva pode ser um dos instrumentos da violência simbólica que a mulher hoje ainda sofre, e um instrumento utilizado essencialmente por ela contra si mesma.

\section{CONSIDERAÇÕES FINAIS}

Diante do que foi aqui apresentado, das análises e das discussões realizadas, pode-se concluir que de maneira geral, os alunos e alunas desta pesquisa apresentaram por meio de suas escritas concepções que reproduzem muitas vezes valores tradicionais, alguns preconceitos, idéias e atitudes padronizadas, às vezes confusas, contraditórias e incoerentes. Alguns mostram uma abertura, um pensar um pouco mais crítico, certa irreverência e contestação diante de determinados assuntos.

Um ponto a salientar é que a ideologia machista parece estar muito presente nas idéias destes alunos e alunas, de modo que muitas vezes ela pôde ser evidenciada no decorrer do trabalho. No tema "Relacionamentos e relações sexuais" ficou exposta a grande dificuldade que principalmente as meninas possuem em dissociar o sexo do amor, isto é, elas acreditam que o que elas chamam de "amor" deve ser condição essencial para que ocorra o ato sexual. Para os meninos isto não parece ocorrer. É como se as meninas, desta faixa etária, ainda esperassem o "príncipe encantado" para poderem se entregar de "corpo e alma". Entretanto, estes "príncipes" podem, enquanto não encontram as suas "princesas", buscar outras experiências sexuais. Na verdade, eles devem buscar outras experiências para testar e provar a virilidade perante os outros e para isso eles não precisam "amar". Às meninas é consentido que elas se relacionem sexualmente, mesmo antes do casamento, não muito precocemente, só se for por amor, "com a pessoa certa, na hora certa". Não é mais necessário que a garota permaneça virgem até o casamento, porém é necessário que ela mantenha um "certo mistério", como disse a aluna F8, e que "não se entregue a qualquer um só pelo prazer do sexo", como dizem no geral. Este é um conteúdo machista reproduzido principalmente pelas meninas que acabam inferiorizando-se. Elas são as mais freqüentes nas categorias que criticam o sexo por prazer, o sexo sem compromisso, o sexo por diversão. Vê-se também que dão grande importância à virgindade, mesmo não defendendo a idéia de preservá-la até o casamento. Diferentemente dos meninos que querem ou se obrigam a "perdê-la". 


\section{REFERÊNCIAS}

BARDIN, L. Análise de conteúdo. Lisboa: Edições 70, 1977.

BOGDAN, R. C.; BIKLEN, S. K. Investigação qualitativa em educação: uma introdução à teoria e aos métodos. Portugal: Porto, 1999.

BOURDIEU, P. A dominação masculina. Rio de Janeiro: Bertrand Brasil, 1999.

KREJCIE, R. V.; MORGAN, D. W. Determining sample size for research activities. Educational and Psychological Measurement, n. 30, p. 607-610, 1970.

SILVA, R. C. da. A falsa dicotomia qualitativo - quantitativo: paradigmas que informam nossas práticas de pesquisa. In: ROMANELLI, G. (Org.). Diálogos metodológicos sobre prática de pesquisa. Ribeirão Preto: Legis Summa, 1998. p. 159-174.

Recebido em: julho de 2007 Aceito em: novembro de 2008 
